\title{
Employee Perspective on Deviant Workplace Behavior and Organizational Climates
}

\author{
Anita Maharani \\ \{anita.maharani@binus.edu\} \\ Universitas Bina Nusantara, Malang ${ }^{1}$
}

\begin{abstract}
The research aimed to measure the relationships between deviant workplace behavior and organizational climate. Method of study is a quantitative approach as our methods of research, and the results were that the workplace is significantly related to the organizational climate, to explore the relationships between deviant workplace behavior and organizational climate. We choose Aero Engineerings company as study object, since it shows relevant phenomena regarding deviant workplace behavior and their organizational climates, and it needs exploration. Findings of this research is that there is a relationship between deviant workplace behavior and organizational climates, although it was a weak relationship.
\end{abstract}

Keywords: deviant, workplace, behavior, organizational, climates, relationships

\section{Introduction}

A company consists of people's run a business to achieve a target that has been set up before. The organization itself is a forum for a group of people who work in a coordinated manner to achieve a common goal [1]. An organization consisting of a group of individuals, using social interaction methods will produce beneficial collaboration for the organization. Therefore, an organization can run well or bad due to several factors, one of which is the Organizational Climate. Organizational climate is a fundamental construction in work and organizational settings because it provides an appropriate context for studying organizational behavior, which allows exploration of individual and group behavior [2]. Thus, it can be concluded that in the company, it will develop along with the organizational climate.

Each individual has a variety of personalities such as perfectionist, critical, impatience, more desires, and so on. Personality is an important factor in the calculation of why employees act according to their performance in organizations or companies and why employees have favorable or unfavorable attitudes toward their work and organization [3]. Thus, it can be concluded that the personality of an employee becomes an important factor of the company in managing its human resources. From the writer's understanding, cultural habits become the basis of the social organization of social life. The social organization system in society consists of norms and roles that direct the interaction between its members. Social norms are taken from two parallel forms, namely behavior, and expectations. Behavioral norms are patterns of actual behavior that are usually followed by individuals who usually follow when interacting under certain conditions, while the expectation norm is what one usually hopes for each other under the given conditions.

The climate of organizing will affect the behavioral habits of employees. Organizational climate is a set of perceptions shared by employees who occupy the same workplace. Organizational climate has several instruments which are separated into eight scales, with two group areas, namely company and human. For the area of the company includes assessment of conditions, organization, innovation, and information, while in the human area includes participation, self-realization, relationships, and direction [4]. Thus, it can be concluded that the organizational climate is influenced by two important instruments, namely the company and 
humans. The description above is a picture of extreme Deviantt behavior, however, Deviantt behavior or known as Deviantt behavior can also manifest beyond the deadline for work, using equipment provided by the company for interests outside the organization, or abilities that are above average.

Human resource management is a series of activities formed with the aim of coordinating human resources in a company [5]. Another definition stated human resource management as a strategic approach to company assets in the form of employees who contribute directly to the achievement of company goals. Community life is strongly influenced by the communication of every human being in a community. Communication is very important as a tool to convey the intent and purpose that someone wants. Each person's communication style must vary according to the person's behavior. A person's behavior can be divided into two types, namely positive and negative behavior, but this assumption arises because of the norms of habits or culture in each community. Basically, if in a community, there are behaviors that are unusual or different from the behavior of most people, it can be said to be Deviant behavior. Irregularities in the workplace have been defined as voluntary behavior that violates organizational norms and thus threatens the goodness of the organization, its members, or both [6].

There are various kinds of differences from deviant behavior from crime, mental illness, and suicide to breaking small rules in school or home, excessive behavior such as overeating, drinking alcohol, to positive forms such as discovery or innovation. Deviant implies a discrepancy, like doing something different from the daily routine. But instead making studies of deviant is intrinsically attractive to most people. Deviant is also very useful in the context of providing scientific contributions that study the behavior of individuals in groups because to understand better the nature that is not suitable and public life in general since the existence of human behavior, at various levels, both appropriate and deviant. Furthermore, deviant analysis can help us to understand the nature of social change. Without Deviant or irregularities, there will be little change, and without change, life will be atrophic and die [7].

In some of the literature, it is stated that the negative deviant is the same as deviant constructive-destructive. Another study makes categorization of norms that norms are closely related to the realization of individual behavior [8]. According to the study, there are two norms, namely informal and formal. If informal norms the intended behavior is routine, while formal norms are expected behavior. Both informal and formal norms apply in groups referred to as referent groups or groups that benefit. The dimensions of deviant constructive-destructive are as follows: treatment of other individuals in the organization, treatment of citizens, treatment of organizational performance, treatment of assets, potential harm to the organization, negative impact of the organization, violation property rights in the organization, changing organizational benefits, organizational functions are becoming more effective, blocking illegal activities in society and organizations, organizational benefits from different opinions, organizational benefits of prosocial behavior, organizational benefits from society [8].

On the other hand, the organizational climate is the overall feeling conveyed by the physical layout, how participants interact, and the way organizational members treat themselves with their customers or other outsiders [9]. In a company has an organization to manage the company to achieve its objectives. In an organization is filled by various kinds of individuals who have various kinds of characters as well, so that it will create a climate of the organization. Organizational climate can be created naturally or directed and shaped by the organization.

Organizational climate as a concept that describes the subjective nature or quality of the organizational environment [9]. These characteristics can be felt or experienced by members of the organization and reported by them in the right question. Organizational climate (OC) is a fundamental construction in work and organizational settings because it provides an appropriate context for studying organizational behavior, which allows exploration of individual and group behavior [10]. Organizational climate is a way of thinking and doing something shared by all members of the organization. The dimensions of organizational climate are as follows: appreciation, warmth, support / commitment, structure, risk and conflict, organizational standards [9]. 
From several journals, as the reference of this research that attracts researchers is a conceptual study which raises the conceptual framework on workplace Deviantce behavior: A Review [11]. In that study was found that when the climate is perceived to be more socially and emotionally supportive, the level of Deviant activity will be low. When the climate becomes the focus for achieving organizational achievement, ignoring employee welfare, employees are more vulnerable to negative behavior.

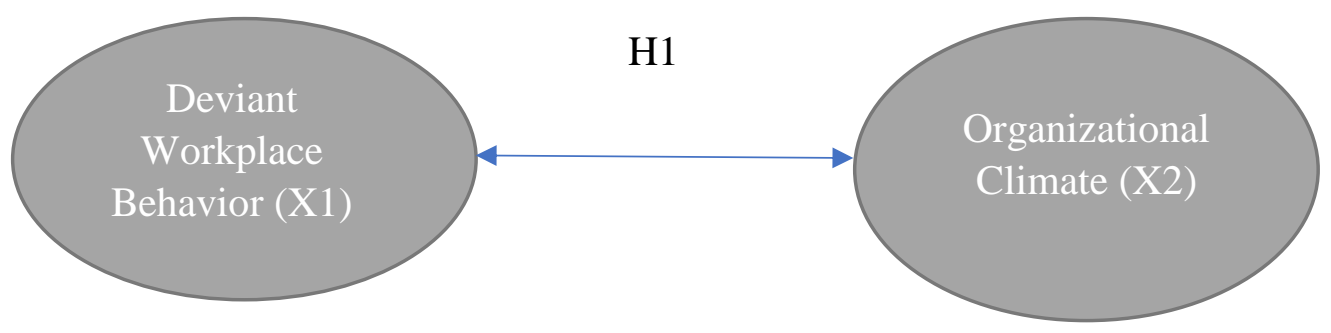

Fig 1. Research Model

H0: There is no deviant behavior relationship and organizational climate in PT GMF AeroAsia Tbk's electromechanical production unit.

H1: There is a relationship between deviant behavior and organizational climate in PT GMF AeroAsia Tbk's electromechanical production unit.

\section{Methodology}

In this study, the population of this study was employees who worked in the PT GMF AeroAsia Tbk electromechanical shop production unit with a total 63 people. Therefore, the sampling technique used is the Convenience Sampling technique. Questionnaires are research techniques that are carried out by distributing questionnaires so that in a relatively short period of time can reach many respondents. Broadly speaking, there are two ways of using, namely disseminated and then filled in by the respondents and used as guidelines for interviews with respondents who use a Likert scale. The answer to each instrument item that uses a Likert scale has a gradation from very positive to very negative, which can be in the form of words including:

Table 1. Score Responds

\begin{tabular}{llc}
\hline No. & \multicolumn{1}{c}{ Respond } & Score \\
\hline 1 & Completely Agree & 4 \\
2 & Agree & 3 \\
3 & Not Agree & 2 \\
4 & Completely Not Agree & 1 \\
\hline
\end{tabular}

In order for this study to be truly valid and accurate, the research questionnaire as the main instrument of this research needs to be tested. This validity concerns the accuracy of the instrument. To find out whether the questionnaire is compiled is valid, it needs to be tested by the correlation between the scores of the item and the total score of the questionnaire. The correlation between the question value is significant, it can be seen using SPSS to test it. For invalid question, items must be removed or not used as a question instrument.

Validity in this study is measured in several ways, namely by using face validity, and by using statistical applications to test it. Face validity sees whether the questions in the research questionnaire are appropriate or not with the variables and indicators that want to be asked, whether all questions have been answered correctly or have been filled in all. Sometimes many 
of the questionnaires that are returned are discarded because they are invalid. This is because the respondent fills in more than one answer. The value of the validity that has been processed from SPSS can be said to be valid if the value of the Pearson Correlation or R-count is greater than the R-table value.

As with validity, reliability can be measured in several ways. This study uses a test and retest procedure. In this way, there are several questions in the questionnaire given which if crosschecked can show reliability in the answers given where if the results are the same, then the questionnaire is reliable because the respondents provide consistent answers. If the value of Cronbach's Alpha is greater than 0.600 , then it can be said that the questionnaire is reliable.

Data analysis methods in this study will use correlation analysis methods using statistical program tools, namely SPSS. Correlation test used in this study is a product moment correlation technique that is useful to find relationships and prove the hypothesis of the relationship of two variables if the data of both variables are in the form of intervals or ratios, and the data sources of two or more variables are the same.

Face validity sees whether the questions in the research questionnaire are appropriate or not with the variables and indicators that want to be asked, whether all questions have been answered correctly or have been filled in all. Sometimes many of the questionnaires that are returned are discarded because they are invalid. This is because the respondent fills in more than one answer. The value of the validity that has been processed from SPSS can be said to be valid if the value of the Pearson Correlation or R-count is greater than the R-table value.

\section{Findings}

Respondents are between age of 20-30 years, while 36 people with a percentage of 57.1 percent, then the second highest number of respondents at the age of 31-40 years 15 people with a percentage of 23.8 percent, then the number of the third most respondents is at the age of 4150 years, amounting to 7 people with a percentage of 11.1 percent, and the number of respondents at least at the age of $>50$ years, amounting to 5 people with a percentage of 7.9 percent.

Respondents can be grouped into two groups according to their gender. The majority of respondents obtained were men, amounting to 62 people with a percentage of 98.4 percent, while female respondents only amounted to 1 person with a percentage of 1.6 percent. Respondents can be divided into two parts based on their marital status. Respondents who were not married or single amounted to 37 people with a percentage of 58.7 percent, while married respondents amounted to 26 people with a percentage of 41.3 percent. It can be concluded that the majority of respondents' status is still unmarried or single.

A total of 24 questionnaire statements on Deviant Workplace Behavior variables represent 12 dimensions, every one dimension contains two statements. Dimensional aspects of Deviant behavior variables if sorted are as follows: (1) Treatment of individuals in the organization, (2) Treatment of the community, (3) Treatment of organizational performance, (4) Treatment of assets, (5) Potential dangerous treatment at the organization, (6) negative impact of the organization, (7) violating the ownership rights of the organization, (8) Providing benefits for change in the organization, (9) Organizational functions are becoming more effective, (10) Blocking illegal activities in the community and organizations, (11) Benefits of the organization from different opinions, (12) Benefits of the organization from prosocial behavior.

Respondents obtained in this study can be seen from the age division, the majority being at the age of 20-30 years, amounting to 36 people with a percentage of 57.1 percent, then the second highest number of respondents at the age of 31-40 years 15 people with a percentage of 23.8 percent, then the number of the third most respondents is at the age of 41-50 years, amounting to 7 people with a percentage of 11.1 percent, and the number of respondents at least at the age of> 50 years, amounting to 5 people with a percentage of 7.9 percent.

Most of the respondents' answers to each statement item in the organizational climate variable, namely the majority agreed as much as 53.1 percent, inversely proportional to the very 
disagreeing answer, only 5.27 percent which means the comparison reaches (1:10). Dimensional aspects of organizational climate variables when sorted are as follows: (1) Awards, including in 4 statements, (2) Warmth, including in 4 statements, (3) Support and commitment, including 4 statements, (4) Structure, includes 3 statements, (5) Risks and conflicts, including 4 statements, (6) Standards, including 3 statements.

The highest mean results are found in the statement "Helping other people without being asked is the thing that gives benefits to the organization" that is equal to 3.35 as the mean. It shows that the electromechanical shop production unit has a perception or habit of behaving to help others without being asked to provide benefits to the organization itself. Then the lowest mean value is found in the statement "Organizational assets can be used for personal purposes" and "Do not have to always convey information honestly to the organization" with a value of 2.06. This value indicates the perception of employees who are considered Deviantt is to use the assets of the organization and not say honestly.

The organizational climate variable obtained the highest mean results in the statement "Friendly atmosphere applies to the organizational environment" with a value of 3.32. This shows that the PT GMF AeroAsia Tbk electromechanical shop production unit has a perception that the atmosphere in the organization's environment is friendly. Furthermore, the lowest mean is in a statemen, "Sometimes it is not clear who has formal authority to take decisions". This means that decision making in the PT GMF AeroAsia Tbk electromechanical shop production area is clear who has formal authority.

Based on the data that has been obtained and then processed, the results of the validity and reliability test are obtained as follows:

Variables of Deviant behavior have twenty-four statements contained in the questionnaire that has been distributed to the intended respondent. It is known from $r$ table in DF $=\mathrm{N}-2$ and probability 0.05 that is according to respondents $63-2=61$, so that the r-value of the table is 0.2480. From the results of statistical calculations, obtained 22 items Deviant behavior variables declared valid because it has corrected item-total correlation $>0.2480$ (r-table) and 2 invalid items, namely Deviant 22 behavior and 24 Deviant behavior because it has a corrected item-total value correlation $<0.2480$ (r-table) so that it will be discarded or eliminated, and only valid items are used to test the hypothesis.

Variables of the organizational climate have twenty-two statements contained in the questionnaire that has been distributed to the intended respondent. Can be known from r-table in $\mathrm{DF}=\mathrm{N}-2$ and probability 0.05 that is according to respondents $63-2=61$, so that the r-table value is 0.2480 . From the results of statistical calculations, obtained 21 one valid statement because it has a corrected item-total correlation $>0.2480$ which can be used in the analysis process and 1 invalid statement that is an organizational climate statement 35 because it has a corrected itemtotal correlation $<0.2480$ so that it is discarded or removed, and only valid items are used to test hypotheses.

Based on the analysis of validity and reliability that has been done, then of the 46 statements submitted in the Deviant behavior measurement questionnaire and organizational climate, it can be concluded that 43 valid statements and also the value of Cronbach's alpha for each variable> 0.6 which means that all instruments in this study it has been reliable. The results of the existing data will then be correlated by using Pearson's product moment correlation with the Statistic Product and Service Solution (SPSS) version 25.0.

Then for the significance test can be obtained by:

If the significance level $<\alpha$, then $\mathrm{H} 0$ is rejected and $\mathrm{H} 1$ is accepted.

If the significance level $>\alpha$, then $\mathrm{H} 0$ is accepted, and $\mathrm{H} 1$ is rejected.

The general hypothesis is shown by Deviant behavioral relationships in the workplace with the organizational climate from the perspective of PT GMF AeroAsia Tbk employees.

Highest mean results are found in the statement "Helping other people without being asked is the thing that gives benefits to the organization" that is equal to 3.35. This shows that the electromechanical shop production unit has a perception or habit of behaving to help others without being asked to provide benefits to the organization itself. Then the lowest mean value is found in the statement "Organizational assets can be used for personal purposes" and "Do not 
have to always convey information honestly to the organization" with a value of 2.06 . This value indicates the perception of employees who are considered Deviantt is to use the assets of the organization and not say honestly.

The organizational climate variable obtained the highest mean results in the statement "Friendly atmosphere applies to the organizational environment" with a value of 3.32. This shows that the PT GMF AeroAsia Tbk electromechanical shop production unit has a perception that the atmosphere in the organization's environment is friendly. Furthermore, the lowest mean is the statement "Sometimes it is not clear who has formal authority to take decisions". This means that decision making in the PT GMF AeroAsia Tbk electromechanical shop production area is clear who has formal authority.

\section{Null Hypotheses $\left(\mathrm{H}_{0}: \rho=0\right)$}

Deviant workplace behavior in the workplace is not significantly related to the organizational climate seen from the perspective of PT GMF AeroAsia Tbk employees.

\section{Research Hypotheses $\left(\mathrm{H}_{1}: \rho \neq 0\right)$}

Deviant workplace behavior in the workplace is significantly related to the organizational climate seen from the perspective of PT GMF AeroAsia Tbk employees. The following are the results of the analysis of the correlation between Deviant behavior in the workplace and the organizational climate seen from the perspective of PT GMF AeroAsia Tbk employees.

Table 2. Correlation Between Deviant Workplace Behavior and Organizational Climate

\begin{tabular}{clrr}
\hline & & \multicolumn{1}{c}{$\begin{array}{c}\text { Deviantt } \\
\text { Workplace } \\
\text { Behavior (X1) }\end{array}$} & $\begin{array}{c}\text { Organizational } \\
\text { Climate (X2) }\end{array}$ \\
\hline Deviantt & Pearson Correlation & 1 & 0,259 \\
Workplace & Sig. (2-tailed) & 63 & 0,040 \\
Behavior (X1) & N & 0,259 & 63 \\
\hline Organizational & Pearson Correlation & 0,040 & 1 \\
Climate (X2) & Sig. (2-tailed) & 63 & 63 \\
& N & & 63 \\
\hline
\end{tabular}

Based on the calculation of Table 2 above, can be obtained coefficient correlation value of 0.259 with a significance level for the general hypothesis of 0.040 at the level of 0.05 or $95 \%$ confidence level, with the level of testing criteria:

1. If the significance level $<\alpha$, then $\mathrm{H} 0$ is rejected and $\mathrm{H} 1$ is accepted

2. If the significance level $>\alpha$, then $\mathrm{H} 0$ is accepted and $\mathrm{H} 1$ is rejected.

Based on the calculation results can be obtained a significance value of $0.04<\alpha(0.05)$ then the working hypothesis of $\mathrm{H} 1$ can be accepted. Thus, it can be concluded that there is a significant relationship between Deviant behavior in the workplace and the organizational climate seen from the perspective of PT GMF AeroAsia Tbk employees. This relationship is indicated by a correlation value of 0.259 , which is included in the low category $(0.20-0.399)$.

The problem to be expressed in this study is whether there is a relationship between Deviant behavior in the workplace and the organizational climate, which is seen from the perspective of PT GMF AeroAsia Tbk employees. The results of this study indicate that there is a relationship between these two variables, namely Deviant behavior with the organizational climate. However, the relationship between the two is weak, which means both of these variables have the potential to be unrelated if triggered by a condition.

The results of this study for Deviant behavior variables show two things that get the lowest response, namely (1) regarding the use of organizational assets and (2) honest, then the organizational climate variable is related to formal decision-making authority. Then for the 
highest response related to Deviant behavior is about initiatives to help others, while for the organizational climate, the highest response is about a comfortable work environment. Warren (2003) made the criteria regarding Deviant behavior, which is constructive and destructive, the results of the study above show that there is a constructive Deviant behavior, which is indicated by the initiative to help others, the desire to be honest with the organization, and not to use organizational assets for personal gain, so this is in line with the concepts put forward by previous study [8].

The results of the study for organizational climate variables show that respondents have a perception that (1) the current work environment is perceived as friendly or family-friendly, (2) employees clearly understand who the decision maker in the work environment is. Organizational members can feel the qualities of the quality of the work environment so that the results of the above study indicate a constructive Deviant behavior, which is indicated by the perception of a family atmosphere in the work environment [9]. The structure is one of the dimensions in the organizational climate. The structure is the level of coercion felt by employees due to structured and structured rules and procedures. This is consistent with the results of this study, where employees assume that there is clarity as to who is the formal authority, the decision maker.

Then based on the results of the test of the significance of Deviant behavior in the workplace and the organizational climate seen from the perspective of employees at PT GMF AeroAsia Tbk. obtained $\alpha$ value of $0.04(\alpha<0.05)$. This shows a significant relationship between Deviant behavior and organizational climate. Thus, it supports the hypothesis that there is a relationship between Deviant behavior and organizational climate in the PT GMF Aeroasia Tbk electromechanical production unit. Thus, it can be concluded that this study has supported the results of research conducted previous study [11] related to what has been stated that there is a significant relationship between organizational climate and destructive and constructive Deviant behavior both individually and collectively.

When compared with nine previous studies, which tested the two variables separately, this study wanted to see whether there was a relationship between two variables, namely 1) Deviant behavior with 2) organizational climate. In the study results, the relationship that occurred in this study was weak. Another study states that there is a functional relationship between individuals and the environment in PT GMF AeroAsia Tbk's electromechanical production unit. In other words, what is indicated by individuals in the form of behavior related to climate in the organizational environment [11]. Although the results of this study state a weak relationship, the concept proposed by the previous study is proven [11].

\section{Conclusion}

Based on the results of research and analysis conducted by researchers regarding Deviant behavioral relationships in the workplace with the organizational climate seen from the perspective of employees at PT GMF AeroAsia Tbk. Especially in electromechanical production units, the following conclusions can be drawn:

1. A description of deviant behavior in the PT GMF AeroAsia Tbk electromechanical production unit more dominant towards constructive Deviant behavior

2. An overview of the organizational climate in PT GMF AeroAsia Tbk's electromechanical production unit, more dominant leads to the nature of kinship and structure.

3. There is a relationship between deviant behavior in the workplace and a weak but significant organizational climate.

4. Thus, the working hypothesis is proven. 


\subsection{Suggestions for Further Research}

The advice that can be given for further research is to examine further whether there are things beyond Deviant behavior that are related to the organizational climate in the company in the field of heavy equipment maintenance. Then further studies can be conducted that explore what factors are driving the emergence of constructive Deviant behavior. Besides, does it have anything to do with the culture related to the organizational climate?

\subsection{Managerial Implications}

Managerial implications addressed to PT GMF AeroAsia Tbk. Especially the production unit of the electromechanical shop in order to find out the phenomenon of existing Deviant behavior and the organizational climate create so that the leaders in the unit can determine their attitude and make decisions based on the phenomena that occur.

Based on the results of the analysis and research that has been carried out on employees in the PT GMF AeroAsia Tbk electromechanical shop production unit, that there is a Deviant behavior phenomenon and is related to the climate of the organization around it. So that how leaders can adjust or make the organizational climate in a better direction in the hope of creating good Deviant behavior for employees, but this must be carried out further study.

\section{References}

[1] G. R. Jones, Organizational Theory, Design and Changer, Texas: Pearson, 2013.

[2] F. Asif, P. S. Elsa, M. Jose dan C. A. Angela, “Assessing organizational climate," Psychometric properties of the CLIOR Scale, pp. 137-144, 2013.

[3] M. G. Jennifer, Understanding and Managing Organizational Behavior, New Jersey: Prentice Hall, 2011.

[4] S. Corral dan J. Perena, Work Climate Questionnaire. Manual, Madrid: TEA Ediciones, 2010.

[5] Byars, Human Resource Management, McGrawhill-Education, 2016.

[6] Robinson, Bennett dan K. P. Dane, "Deviant Workplace Behavior and The Organization's Ethical Climate," Journal of Business and Psychology, pp. 47-48, 2002.

[7] P. Stuart dan A. H. John, Deviant Behavior Patterns, Sources, and Control, New York: Springer, 1990.

[8] E. D. Warren, "Constructive and Destructive Deviance in Organizations," The Academy of Management Review, Vol. 28. No. 4, pp. 622-632, 2003.

[9] P. Kanten dan F. Er Ulker, "The Effect of Organizational Climate on Counterproductive Behaviors: An Empirical Study on the Employees of Manufacturing Enterprises," The Macrotheme Review, pp. 144-160, 2013.

[10] E. Pena-Suarez, "Assessing organizational climate," Psychometric properties of the CLIOR Scale, pp. 137-144, 2013.

[11] K. Narayanan dan E. S. Murphy, "Conceptual Framework on Workplace Deviance Behaviour: A Review," Journal of Human Values, pp. 218-233, 2017.

[12] S. L. Robinson dan R. J. Bennet, "A typology of deviant workplace behaviors: A multidimensional scaling study," Academy of Management Journal, pp. 555-572, 1995.

[13] P. Stuart dan A. H. John, Deviant Behavior Patterns, Sources, and Control, New York: Springer, 1990. 